\title{
Prostate Cancer cT2 TNM Finding v7
}

National Cancer Institute

\section{Source}

National Cancer Institute. Prostate Cancer CT2 TNM Finding v7. NCI Thesaurus. Code C89214.

Prostate cancer confined within the prostate. Tumor found in one or both lobes by needle biopsy, but not palpable or reliably visible by imaging, is classified as T1c. (from AJCC 7th Ed.) 